\title{
Selective Expression of an Endogenous Lactose-Binding Lectin Gene in Subsets of Central and Peripheral Neurons
}

\author{
Mary A. Hynes, ${ }^{1}$ Michael Gitt, ${ }^{2}$ Samuel H. Barondes, ${ }^{2}$ Thomas M. Jessell, ${ }^{1}$ and Linda B. Buck ${ }^{1}$ \\ "Howard Hughes Medical Institute and Center for Neurobiology, Columbia University, College of Physicians and \\ Surgeons, New York, New York 10032, and 2Department of Psychiatry, University of California, San Francisco, \\ California 94143
}

\begin{abstract}
Cellular interactions in a variety of vertebrate non-neural tissues are thought to be mediated by cell surface carbohydrate structures. The detection of cell-specific surface carbohydrates and carbohydrate-binding proteins within the embryonic nervous system has raised the possibility that carbohydrate recognition may also contribute to the interactions of developing neurons. Soluble lactose-binding lectins constitute one class of carbohydrate-binding proteins expressed in the vertebrate nervous system. We describe here the isolation of CDNAs from rat brain libraries encoding one of these lectins, RL-14.5, and demonstrate that this protein is not only homologous to other soluble lectins, but also identical in primary sequence to a lectin present in at least one non-neural tissue. RNA blot analysis and in situ hybridization reveal a restricted pattern of expression of RL-14.5 mRNA within the rat nervous system. High levels of RL-14.5 mRNA are present in primary sensory neurons and motoneurons in the spinal cord and brain stem. Moreover, expression of RL-14.5 mRNA in sensory and motoneurons is detectable soon after neuronal differentiation. These findings, together with previous studies demonstrating the selective expression of oligosaccharide ligands for RL-14.5 on the same neurons, are consistent with the idea that carbohydrate-mediated interactions contribute to the development of this subset of mammalian neurons.
\end{abstract}

Intercellular recognition and adhesion is initiated by the binding of surface proteins with complementary ligands. Frequently, these ligands are proteins; however, cell surface carbohydrates have also been shown to play a critical role in cell interactions in several vertebrate systems. For example, during fertilization, the binding of sperm to oocytes results from the interaction of sperm surface proteins with oligosaccharides on the ZP-3 glycoprotein in the zona pellucida coat surrounding the oocyte (Wassarman, 1987; Bleil and Wassarman, 1988). At later stages of preimplantation development, the adhesion of mouse blas-

\footnotetext{
Received Aug. 29, 1989; revised Oct. 12, 1989; accepted Oct. 13, 1989.

We thank Jurgen Brosius for providing rat brain cDNA libraries. Kim Huang, Sumayah Jamal, and Leslie Miller provided excellent technical assistance. We are grateful to Richard Axel for his valuable comments and support, to Marc TessierLavigne for critical comments, and to Rita Lenertz and Marion Richman for preparing the manuscript. This work was supported by the Howard Hughes Medical Institute and by grants from The McKnight Foundation and NIH. T.M.J. is an Investigator of the Howard Hughes Medical Institute.

Correspondence should be addressed to Dr. Thomas M. Jessell at the above address.

Copyright (C) 1990 Society for Neuroscience $0270-6474 / 90 / 031004-10 \$ 02.00 / 0$
}

tomeres appears to involve carbohydrate recognition events that can be modified by perturbing specific oligosaccharide structures (Fenderson et al., 1984; Rastan et al., 1985). In addition, the homing of subsets of lymphocytes to specific lymphoid organs involves the recognition of oligosaccharides on endothelial target cells by carbohydrate-binding proteins on the lymphocyte surface (Rosen and Yednock, 1986; Siegelman et al., 1989; Lasky et al., 1989).

The contribution of carbohydrates to cellular interactions within the nervous system is less clear. Specific carbohydrate structures have been identified on subsets of embryonic and adult neurons (Levine et al., 1984; Yamamoto et al., 1985; Jessell and Dodd, 1986; Blum and Barnstable, 1987). Moreover, the restricted localization of some of these carbohydrates correlates with the physiological properties and projection patterns of neurons. For example, subsets of rat dorsal root ganglion (DRG) neurons that convey different sensory modalities and project to different target regions in the spinal cord (Brown, 1981; Perl, 1983), possess different classes of cell surface oligosaccharides (Dodd et al., 1984; Dodd and Jessell, 1985; Chou et al., 1989). Interestingly, many of the DRG subset-specific oligosaccharides are lactosamine-based structures that are similar or identical to the structures implicated in fertilization and blastomere adhesion.

Several different carbohydrate binding proteins have been identified within the nervous system (Simpson et al., 1977; Kobiler et al., 1978; Eisenbarth et al., 1978; Regan et al., 1986; Joubert et al., 1987; Zanetta et al., 1987; Kuchler et al., 1988) Two of these are soluble (non-membrane-bound) lectins that bind lactosamine-based carbohydrate structures (Barondes, 1984). Soluble lectins have been detected in a variety of cell types where they can be seen in the cytoplasm and appear to be secreted (Beyer and Barondes, 1982; Cerra et al., 1984). Upon isolation, these molecules can mediate the agglutination of a variety of different cell types (Barondes, 1984). Immunohistochemical analysis indicates that, within the rat nervous system, the 2 lactose-binding lectins RL-14.5 and RL-29 are expressed with a high degree of selectivity, primarily within primary sensory and motor neurons (Regan et al., 1986). The coincident expression of surface lactoseries oligosaccharides and lactosebinding lectins by DRG neurons early in development raises the possibility that soluble lectins are involved in mediating specific interactions among this set of neurons during development.

The RL-14.5 and RL-29 lectins belong to a family of structurally related proteins that are found in both neurons and nonneural cells (Barondes, 1984; Paroutaud et al., 1987; Leffler et 
al., 1989). In order to gain information on the nature of neuronal lactose-binding lectins, we isolated a series of rat nervous system cDNA clones encoding RL-14.5. We have determined the primary structure of the neural RL-14.5 lectin and examined the expression pattern of the gene encoding this lectin by RNA blot analysis and in situ hybridization, focusing on the nervous system. We describe here that RL-14.5 mRNA is expressed in a highly restricted fashion in the nervous system, confined predominantly to primary sensory neurons and motoneurons in the embryonic and adult spinal cord and brain stem.

\section{Materials and Methods}

Isolation and sequence analysis of neural lectin cDNAs. Adult rat brain cDNA libraries kindly provided by Jurgen Brosius or obtained from Clontech were screened by the filter hybridization method (Maniatis et al., 1982) with a ${ }^{32}$ P-labeled (Weinstock et al., 1978) cDNA fragment (Hep-2) encoding a protein recognized by antibodies against RL-14.5 (Gitt and Barondes, 1986). In addition, a $\lambda$ GT11 cDNA expression library prepared from RNA of E15 spinal cord (S. Temple and T. M. Jessell, unpublished observations) was screened with antibodies against RL-14.5 (Cerra et al., 1984) using published procedures (Young and Davis, 1983; Snyder and Davis, 1985). cDNAs were subcloned into M13 vectors (Vierira and Messing, 1982) and sequenced using the dideoxy chain-termination technique (Sanger et al., 1977).

RNA blot hybridization. Polyadenylated RNA (Poly A+ RNA) was isolated as described (Chirgwin et al., 1977; Lund et al., 1986), sizefractionated on agarose gels, and transferred to Gene Screen (NEN). RNA blots were hybridized as previously described (Lund et al., 1986) using a $5^{\prime}$ Eco RI fragment of the RL-14.5 cDNA (nucleotides 1-369) as probe. The RL-14.5 cDNA fragment was labeled with ${ }^{32} \mathrm{P}$ by nick translation to a specific activity of $10^{8} \mathrm{cpm} / \mu \mathrm{g}$ (Rigby et al., 1977). Two single-stranded synthetic DNA oligonucleotides (27 and $36 \mathrm{nt}$ ) representing nucleotides $312-338$ and $390-425$ of $\lambda$ GT10J9 cDNA (Fig. 1) were also used as probes with similar results (not shown). The oligonucleotides were labeled with ${ }^{32} \mathrm{P}$ using polynucleotide kinase (Maniatis et al., 1982) and purified on $15 \%$ polyacrylamide gels containing $7 \mathrm{M}$ urea (Maxam and Gilbert, 1977). After determination of RL-14.5 mRNA levels, blots were stripped of RL-14.5 probe and reprobed with a ${ }^{32} \mathrm{P}$ labeled cDNA encoding rat actin, to control for the amount of RNA loaded onto each lane of the gel. The relative amounts of RL-14.5 reported in the text are for tissues which showed a similar abundance of actin mRNA (except for liver, which contains much lower levels of actin mRNA than other tissues).

Localization of RL-14.5 mRNA in the nervous system by in situ hybridization. Adult rats were anesthetized with sodium pentobarbital $(60$ $\mathrm{mg} / \mathrm{kg}$, i.p.) and perfused through the ascending aorta with PBS $(0.15$ $\mathrm{M} \mathrm{NaCl}$ in $10 \mathrm{~mm}$ sodium phosphate, $\mathrm{pH} 7.4$ ) followed by $100 \mathrm{~mL} / 100$ gm body weight of fixative (4\% paraformaldehyde in $0.1 \mathrm{M}$ phosphate buffer, $\mathrm{pH}$ 7.4). Immediately after perfusion, tissues were removed, immersed in fixative for a further $3 \mathrm{hr}$, and placed in PBS containing $30 \%$ sucrose for $12-18 \mathrm{hr}$ at $4^{\circ} \mathrm{C}$. Embryonic rats were killed by decapitation, fixed by immersion in $4 \%$ paraformaldehyde for $3 \mathrm{hr}$ and placed in PBS-sucrose for $12-18 \mathrm{hr}$ at $4^{\circ} \mathrm{C}$. After sucrose infiltration, tissues were rapidly frozen and $8-15 \mu \mathrm{m}$ sections were cut using a cryostat. Sections were thaw-mounted onto slides subbed with gelatin/poly-1lysine and stored at $4^{\circ} \mathrm{C}$ for $16-48 \mathrm{hr}$.

Sections were prehybridized in a buffer containing $50 \%$ deionized formamide, $0.6 \mathrm{M} \mathrm{NaCl}, 0.02 \%$ Ficoll and polyvinylpyrolidone (PVP), $0.1 \%$ BSA, $10 \mathrm{~mm}$ Tris- $\mathrm{HCl}(\mathrm{pH} 7.0), 1 \mathrm{~mm}$ EDTA (pH 7.0), and denatured salmon sperm DNA (ssDNA; $0.5 \mathrm{mg} / \mathrm{ml}$ ), yeast total RNA $(0.5 \mathrm{mg} / \mathrm{ml})$, and yeast $\mathrm{tRNA}(0.5 \mathrm{mg} / \mathrm{ml})$. Prehybridization was carried out for $2.5 \mathrm{hr}$ at $50^{\circ} \mathrm{C}$ in an atmosphere saturated with buffer consisting of $4 \times$ SSC and $50 \%$ formamide. After prehybridization, sections were rinsed in $4 \times$ SSC and hybridized in a buffer similar to the prehybridization buffer with the following changes: bovine serum albumin was added to a final concentration of $0.02 \%$, ssDNA to $0.1 \mathrm{mg} / \mathrm{ml}$, total yeast RNA and yeast tRNA to $0.05 \mathrm{mg} / \mathrm{ml}$, and dextran sulfate to $10 \%$.

Single-stranded sense and antisense RL-14.5 RNA probes were synthesized and labeled by in vitro transcription of a $5^{\prime} 369 \mathrm{nt}$ Eco R1 fragment of the $\lambda$ GT10J9 cDNA which had been subcloned into the Bluescript vector (Stratagcnc). Transcription was initiated from vector T3 and T7 bacteriophage promoters. Probes were denatured by boiling for $2 \mathrm{~min}$ and added to $1 \times$ hybridization buffer at $0.5-4 \times 10^{6} \mathrm{cpm} /$ $150 \mu \mathrm{l}$, and slides were hybridized for $14-16 \mathrm{hr}$ at $50^{\circ} \mathrm{C}$. Slides were successively washed for $30 \mathrm{~min}$ at $50^{\circ} \mathrm{C}$ in $2 \times \mathrm{SSC}$, digested with RNase A $(30 \mu \mathrm{g} / \mathrm{ml})$ at $37^{\circ} \mathrm{C}$ for $60 \mathrm{~min}$ in $0.5 \mathrm{M} \mathrm{NaCl}, 10 \mathrm{~mm}$ Tris, $\mathrm{pH} 7.5$ (to remove nonspecifically bound single-stranded RNA probe), washed for $3 \mathrm{hr}$ at $50^{\circ} \mathrm{C}$ in 4 liters of $0.1 \times \mathrm{SSC}, 0.05 \% \mathrm{Na}$-pyrophosphate, and $14 \mathrm{~mm} \beta$-mercaptoethanol, and then washed overnight in the same buffer which was allowed to cool slowly to room temperature. Slides were dehydrated through an ascending series of ethanols, air-dried, and dipped in Kodak NTB-2 photoemulsion diluted 1:1 with distilled water. When dried, the slides were stored in light-tight boxes and allowed to expose for $5-21$ d at $4^{\circ} \mathrm{C}$. Slides were developed with Kodak D-19 developer, fixed, washed, air-dried, and stained with cresyl violet-acetate. After staining, sections were dehydrated in ascending ethanol series, cleared with xylene, and coverslipped with permount. Autoradiographic grains were visualized with a Zeiss photomicroscope equipped with bright- and dark-field optics.

\section{Results}

Isolation of $R L-14.5$ lectin $C D N A$

Our previous immunocytochemical studies showed that subsets of central and peripheral neurons express a lectin of approximately $14 \mathrm{kDa}$ that is recognized by antisera raised against a rat lung lectin of similar size (RI -14.5; Cerra et al., 1984; Regan et al., 1986). cDNA clones encoding a $14 \mathrm{kDa}$ lectin isolated from rat lung have been isolated and sequenced (Clerch et al., 1988). Since multiple isoforms of $14 \mathrm{kDa}$ lactose-binding lectins have been reported in mammalian tissues (Fitzgerald et al., 1984), it was possible that the $14 \mathrm{kDa}$ lectin present in neurons is immunologically related to, but structurally distinct from, the protein found in non-neural cells. To address this question and to provide further information on the structure and expression of the neural $14 \mathrm{kDa}$ lectin, we isolated cDNA clones encoding the $14 \mathrm{kDa}$ lectin present in the rat nervous system.

Adult rat brain $\lambda \mathrm{GT} 10$ and $\lambda \mathrm{GT} 11$ cDNA libraries were screened with a cDNA designated Hep-2 that was isolated from a HEP-G2 hepatoma cDNA library (Gitt and Barondes, 1986). The Hep- 2 cDNA is similar or identical to the sequence of the cDNA encoding a mouse $14 \mathrm{kDa}$ lectin (Wilson et al., 1989). In addition, a $\lambda$ GT 11 cDNA library constructed from embryonic day 15 rat spinal cord RNA was screened with antisera generated against the RL-14.5 lectin isolated from rat lung (Cerra et al., 1984). A series of cDNA clones identified with antibody or cDNA probes were sequenced. All appeared to derive from the same mRNA species. The nucleotide sequence of the longest of these putative RL-14.5 cDNA clones, $\lambda$ GT10J9, is shown in Figure 1. Other, shorter cDNA clones were identical in sequence to portions of $\lambda \mathrm{GT} 10 \mathrm{~J} 9$. The sequence of $\lambda \mathrm{GT} 10 \mathrm{~J} 9$ contains a single long open reading frame of 405 nucleotides (nt) which is preceded by a 53 nucleotide $5^{\prime}$ untranslated region and is followed by $64 \mathrm{nt}$ of $3^{\prime}$ untranslated sequence, which includes a polyadenylation signal at nucleotides $490-495$, and a poly $A$ tail of about 44 nucleotides. A single mRNA species of $0.65 \mathrm{~kb}$ was detected by Northern blot analysis using the $\lambda$ GT $10 \mathrm{~J} 9 \mathrm{cDNA}$ as a probe (see below), indicating that the $\sim 566 \mathrm{nt}$ sequence of $\lambda$ GT10J9 lacks only a short region of the $5^{\prime}$ untranslated sequence and/or of the poly A tract. $\lambda \mathrm{GT} 10 \mathrm{~J} 9$ encodes a protein of approximately $14.9 \mathrm{kDa}$ that is highly homologous to $14-16$ $\mathrm{kDa}$ lactose-binding lectins isolated from several other species (see below). Moreover, the nucleotide sequence of $\lambda$ GT10J9 cDNA isolated from rat brain is identical to that of a cDNA which encodes the rat lung lectin, RL-14.5 (Clerch et al., 1988). Therefore, the $14.5 \mathrm{kDa}$ lectins expressed in the nervous system and at least one non-neural tissue are identical in primary se- 
ATGCCCGTCTGACAGCTGGTGGAGCAGGTCGCAGGAATCTCTTCGCTTCAATC

Met Ala Cys Gly Leu Ual fla Ser Aon Leu fion Lou Lyo 13 54 ATG GCC TGT GGT CTG GTC GCC AGC RAC CTG ART CTC ARA Pro Gly Glu Cys Leu Lys Val Arg Gly Glu Lou Ala Pro 26 93 CCT GGG GAR TGT CTC RAA GTT CGG GGA GRG CTG GCC CCG Asp fla Lye Ser Phe Ual Leu fson Leu Gly Lys Asp Ser J9 132 GRC GCC ARG AGC TTT GTG TTG ARC CTG GGG RAR GRC AGC Asn Asen Leu Cys Leu Hls Phe fen Pro Rig Phe fon Ala 52 171 AAC AAC CTG TOC CTR CAC TTC AAC CCC CGC TTC AAC GCC HIs Gly Asp Ala Asn Thr lle Ual Cys fan Sor Lys Rap 65 210 CAC GGA GAT GCC AAC ACC RTT GTG TGT RAC RGC ARG GAC Rep Gly Thr Trp Gly Thr Glu Gln Arg Glu Thr Ald Phe $7 \theta$ 249 GAT GGG ACC TGG GGA ACR GAR CAR CGG GAG ACT GCC TTC Pro Phe Gin Pro Gly Ser lle Thr Glu Ual Cyo lle Thr 288 CCT TTC CAG CCT GGG AGC ATC ACG GAG GTG TGC ATC RCC

Phe Rap Gln Ala Aop Leu Thr Ilo Lys Leu Pro Rap Gly 104 $32 ?$ TTT GAC CAG GCT GAC CTG ACC ATE RAG CTG CCA GRC GGG

HIs Glu Phe Lys Phe Pro Ren frg Leu fen Met Glu Ala 11 T 366 CAT GAR TTC ARA TTC CCC RAC CGC CTC RAC RTG GRG GCC

Ile Asn Tyr Met Ala Ala Asp Gly Rop Phe Lys lle Lys 130 405 ATC ARC TRC RTG GCG GCG GRT GGT GAC TTC ARG ATT RAG

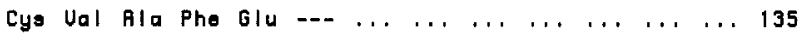
444 TGT GTG GCC TTT GAG TGA RGC CAG CCA GCC CCA GCC CGT

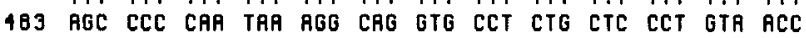
$\cdots$.

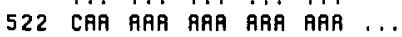

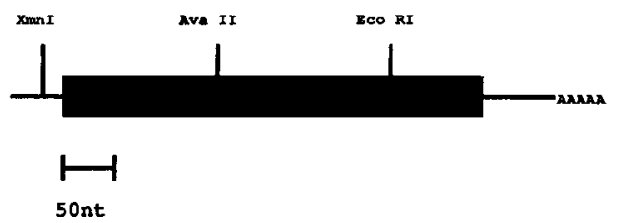

Figure 1. Nucleotide sequence of rat neural $14.5 \mathrm{kDa}$ lactose bindinglectin cDNA and deduced amino acid sequence. Nucleotides are numbered in the left margin starting with the first base of the ATG initiator codon. $\Lambda$ mino acids are numbered in the right margin. $\Lambda$ diagrammatic representation of $\lambda \mathrm{GT} 10 \mathrm{~J} 9 \mathrm{cDNA}$ is shown below.

quence. The amino acid sequence predicted by RI -14.5 cDNA does not contain a stretch of hydrophobic amino acids at the amino-terminus that could serve as a classical signal sequence.

A comparison of the deduced amino acid sequence of RL14.5 with that of 14-16 kDa lactose-binding lectins from other mammalian species is shown in Figure $2 a$. It is 93 and $90 \%$ identical to the predicted sequences of lectins present in mouse fibroblasts and human placenta, respectively (Hirabayashi and Kasai, 1988; Couraud et al., 1989; Wilson et al., 1989). RL14.5 also exhibits a high degree of homology with similarly sized lactose-binding lectins from chicken and eel (Fig. 2a). The majority of the invariant amino acid residues lie in the $\mathrm{N}$ terminal two-thirds of the molecule. Among these is a tryptophan residue (position 69) which, on the basis of chemical modification studies, is thought to lie in or near the carbohydrate-recognition site (Levi and Teichberg, 1981).

RL-14.5 also exhibits structural similarities with a larger ( $~ 30$ $35 \mathrm{kDa}$ ) lactose-binding lectin of mouse termed CBP-35 (Jia and Wang, 1988) and with a rat IgE binding protein (Albrandt et al., 1987), which is probably the rat homolog of CBP-35 (Fig.
$2 b$ ). The rat IgE binding protein, in fact, appears to be identical to the rat lung lectin, RL-29, which is expressed in DRG neurons (Regan et al., 1986; Albrandt et al., 1987; Leffler et al., 1989; Poulter et al., personal communication). The carboxy-terminal domain of each of these is homologous to RL-14.5 (Fig. 2b). The partial amino acid sequences of additional lactose-binding lectins of 14-19 $\mathrm{kDa}$ isolated from rat intestine (Leffler et al., 1989) indicates that there are several other members of this lectin family.

\section{Neural distribution of $R L-14.5 \mathrm{mRNA}$}

The pattern of expression of RL-14.5 mRNA in different tissues and during neuronal development was determined initially by Northern blot analysis. A single band with an estimated size of $0.65 \mathrm{~kb}$ was detected at approximately equivalent abundance in both neural and non-neural tissues on embryonic day (E) 13 (day of sperm plug is designated as E0; (Fig. 3). We did not determine the regional distribution of RL-14.5 mRNA expression in the nervous system by RNA blot analysis at this developmental stage. By postnatal day (P) 0-4, however, RL-14.5 mRNA was detectable at much higher levels in the DRG and spinal cord than in the brain (Fig. 3). This quantitative difference in mRNA was maintained in the adult nervous system (Fig. 4). The highest levels of expression of RL-14.5 mRNA were detected in the DRG and spinal cord. Examination of RNAs prepared from different regions of the brain further showed that brain stem contains higher levels of RL-14.5 mRNA than other brain regions. The midbrain, cerebellum, and hypothalamus contain much lower but still detectable levels of RL-14.5 mRNA, whereas the cerebral cortex, hippocampus, and corpus striatum contain barely detectable levels of this mRNA (Fig. 4). The high level expression of RL-14.5 mRNA within the DRG and spinal cord did not appear to change markedly during development (Figs. 3, 4). High levels of RL-14.5 mRNA were also detected in many non-neural adult tissues, including lung and heart (Fig. 3). These findings provide further evidence that RL-14.5 exists as a single molecular species in neurons and non-neural tissues but that in the nervous system the levels of expression of the lectin vary considerably in different regions.

\section{Cell-specific expression of $R L-14.5$ within the nervous system}

We next determined the identity and location of cells that synthesize RL-14.5 mRNA within the central and peripheral nervous system by in situ hybridization. In these experiments, ${ }^{35} \mathrm{~S}$ labeled anti-sense RNA was transcribed in vitro from a vector containing nucleotides 1-374 of RL-14.5. Labeled sense strand RNA prepared from the same segment was used as a control in these experiments. No specific hybridization was observed using sense RNA as probe (Fig. $6 b$ ).

In addition, since RL-14.5 is only one of a family of structurally related lactose-binding lectins, oligonucleotide probes were used to exclude the possibility of cross-hybridization with other family members. The 2 oligonucleotides employed correspond to nucleotides $312-338$ and $390-425$ of $\lambda$ GT $10 J 9$ (Fig. 1), and are in regions that do not exhibit homology to CBP-35 or the rat IgE binding protein (Fig. $2 b$ ). The distribution of labcled cclls detcetcd with these DNA probes was identical, at all ages, to the distribution detected using RNA probes transcribed in vitro from RL-14.5 cDNA.

Hybridization to cryostat sections of central and peripheral neural tissues revealed the presence of RL-14.5 mRNA only in neurons. The location of labeled neurons was in agreement with 
2

Rat Brain

Mouse 3 T3

Hum Plac

Chick sk

EEL

Rat Brain

Mouse 373

Hum Plac

Chick sk

EEL

Rat Brain

Mouse $3 T 3$

Hum Plac

Chlck sk

EEL

Rat Brain

Mouse 3 T 3

Hum Plac

Chick sk

EE I

b

Rat Brain

Hum Hep-1

Mouse CBP-35

Rat IgE BP

Rat Bratn

Hum Hep-1

Mouse CBP-35

Rat IgE BP

Rat Brain

Hum Bep-1

Mouse CBP-35

Rat IgE BP

Rat Brain

Hum Hep-1

Mouse CBP-35

Rat IgE BP
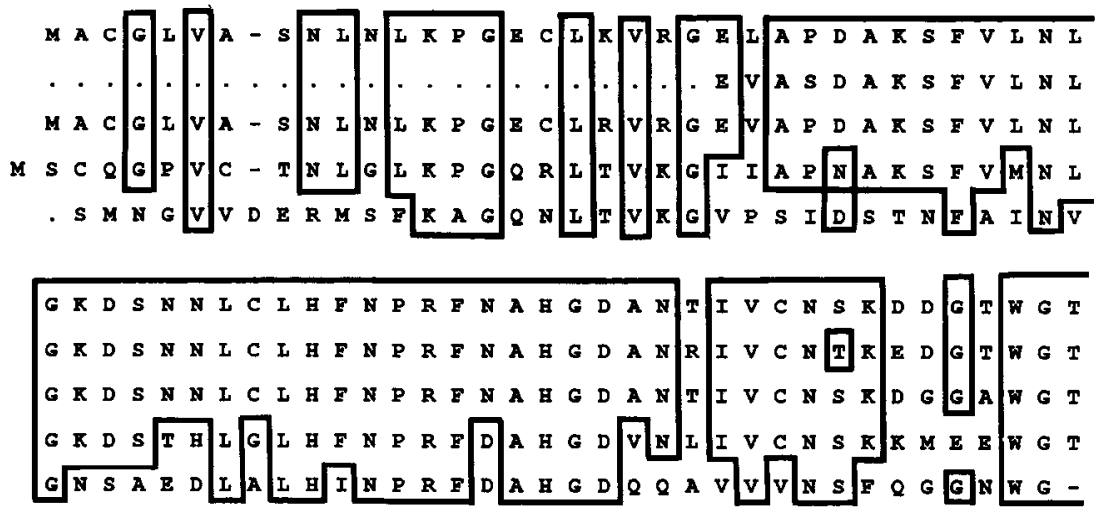

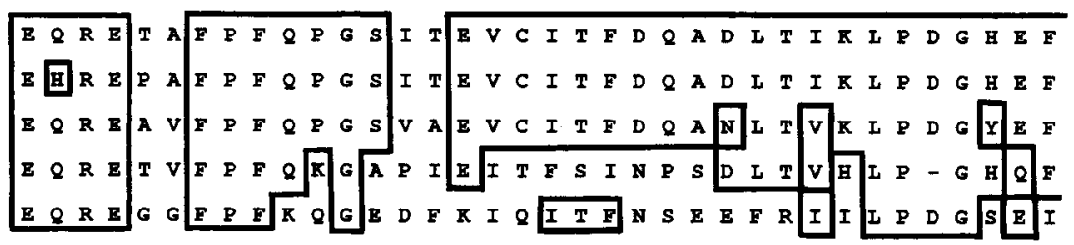

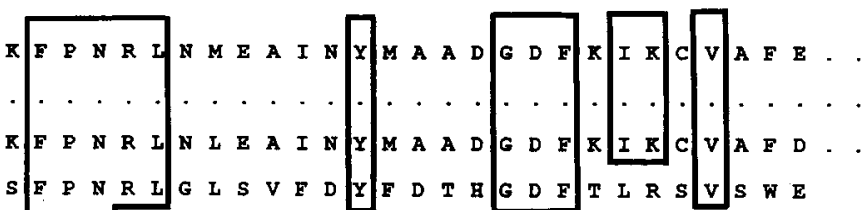

H F P N N R R Y M H F E G E A R I Y S - I E I K

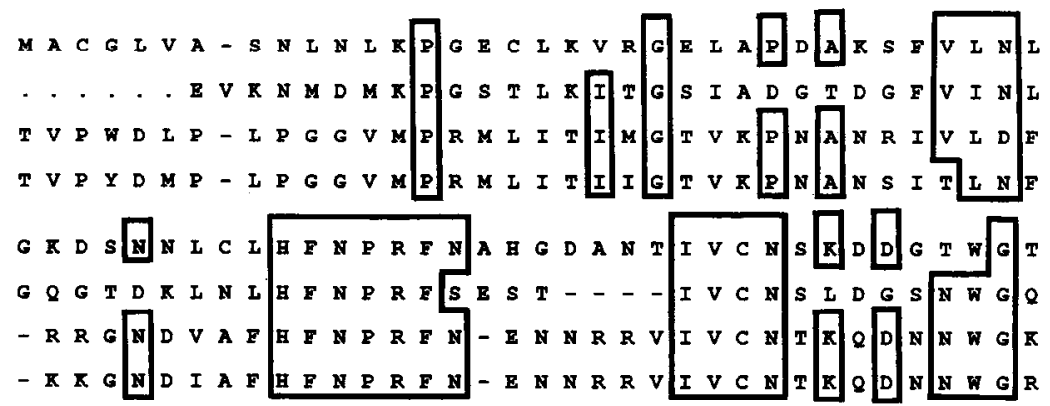

E R E T A F E F $Q$ P GS I T E V C I T F D Q A D I T I K L P D G E

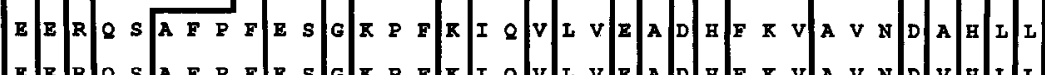
E

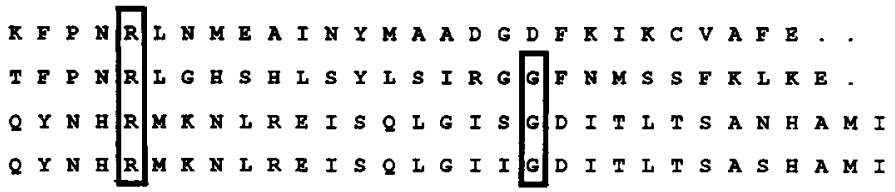

Figure 2. Amino acid sequence conservation between RL-14.5 and homologous proteins. $a$, Alignment of the amino acid sequences of $\sim 14 \mathrm{kDa}$ lactose-binding lectins isolated from different species. Invariant amino acids are boxed. Sequences were obtained from mouse 3T3 (Wilson et al., 1989); human placenta (Hirabayashi and Kasai, 1988), chick (Ohyama et al., 1986), and eel (Paroutaud ct al., 1987). b, Alignment of the sequence of RL-14.5 with homologous proteins of higher or undetermined molecular weight including human Hepl (Gitt and Barondes, 1986); the carboxy-terminal region (amino acids 127-262) of mouse CBP-35 (Jia and Wang, 1988) and of the carboxyterminal region (amino acids 128-263) of the rat $\mathrm{IgE}$ binding protein (Albrandt et al., 1987). the regional distribution of mRNA detected by RNA blot analysis. In the PNS, high levels of expression were detected in DRG neurons from early stages of development ( $\sim$ E13). Essentially all neurons in the DRG of E18 embryos appeared to express RL-14.5 mRNA (Fig. 5a) with no detectable differences in the levels of expression in subpopulations of sensory neurons at this stage. Expression of RL-14.5 mRNA persists in essentially all DRG neurons at later developmental stages and is maintained in adult sensory neurons (Fig. 6). The levels of mRNA, estimated by autoradiographic grain density, appeared greater in intermediate- and small-diameter neurons (Fig. 6c). Specific hybridization could not be detected in satellite cells in the DRG or in cells in the dorsal root or peripheral nerve, suggesting that RL-14.5 mRNA expression in the DRG is restricted to neurons. Hybridization to sympathetic neurons in the superior cervical ganglion of adult rats was much less prominent than to sensory 


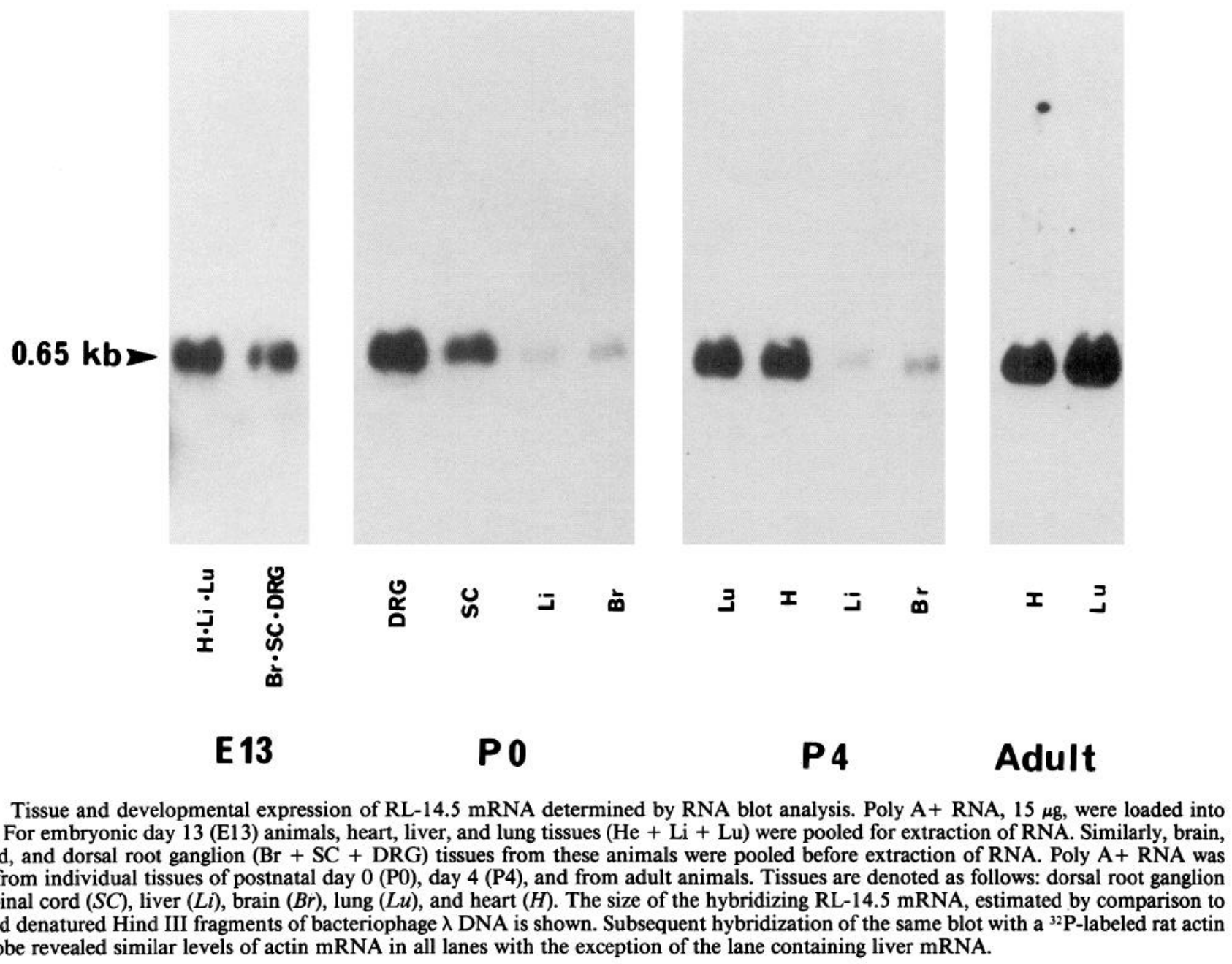

Figure 4. Regional distribution of RL14.5 in the adult rat nervous system as determined by RNA blot analysis. In the first 3 lanes, $8 \mu \mathrm{g}$ poly A+ RNA was loaded. In the next 7 lanes, $15 \mu \mathrm{g}$ poly A+ RNA isolated from different regions of adult brain was loaded into each lane. Brain regions are denoted as follows: brain stem $(B r S t)$, cortex $(C t x)$, cerebellum $(C B)$, midbrain (Mid $B r)$, hippocampus $(\mathrm{Hi})$, striatum $(\mathrm{Str})$, and hypothalamus (Hyp). The size of the RL-14.5 mRNA transcript was estimated by comparison to labeled and denatured Hind III fragments of bacteriophage $\lambda$ DNA.
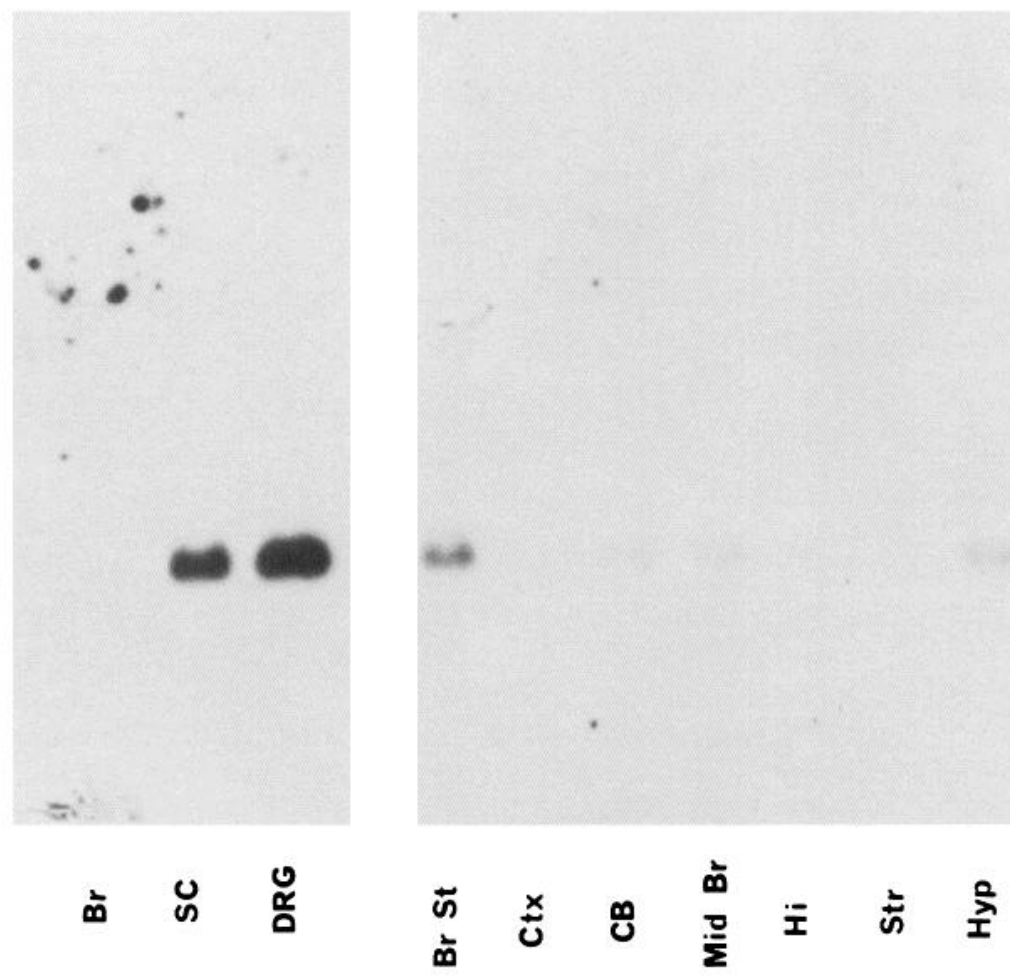

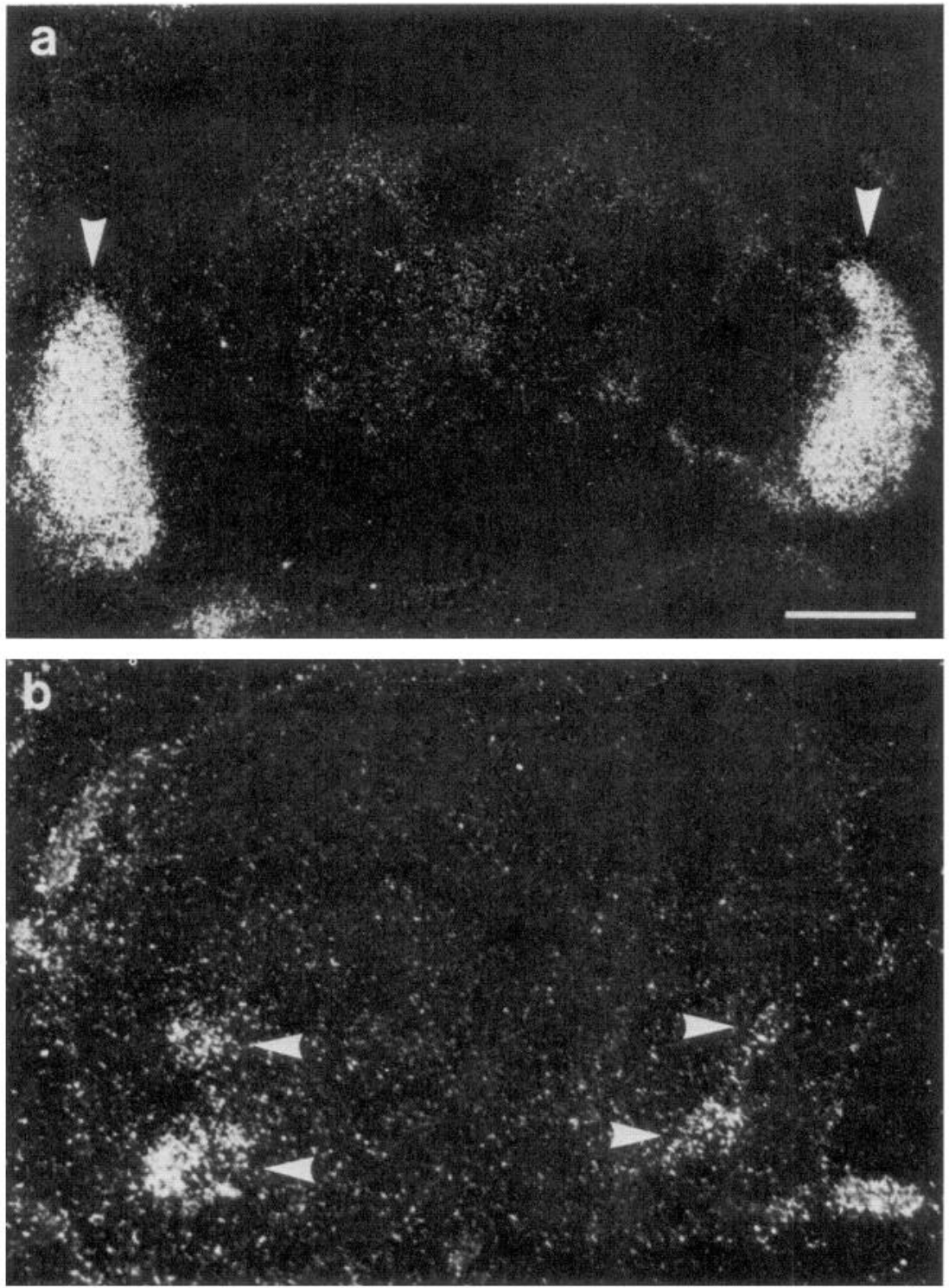

Figure 5. Localization of RL-14.5 mRNA in the spinal cord and DRG of E18 rat embryo by in situ hybridization. $a$, Low-power, dark-field photomicrograph showing strong hybridization in the DRG of an E18 rat embryo (arrowheads). Silver grains appear white under dark-field illumination. Scale bar, $200 \mu \mathrm{m}$ in $A, 150 \mu \mathrm{m}$ in $B . b$, Higherpower, dark-field photomicrograph of E18 spinal cord. Within the spinal cord there is an accumulation of silver grains in the ventral spinal cord over regions occupied by developing motoneurons (arrowheads). The density of silver grains seen over other regions of the spinal cord is not significantly different from background. neurons (not shown), and we could not resolve whether these signals reflected specific or background labeling. Sympathetic ganglion neurons express levels of RL-14.5 immunoreactivity that are not distinguishable from that detected by labeling with preimmune sera (Regan et al., 1986).

The localization of RL-14.5 mRNA in the PNS detected by in situ hybridization is similar to the distribution of the RL14.5 protein detected immunocytochemically (Regan et al., 1986). Small- and intermediate-diameter DRG neurons express higher levels of RL-14.5 immunoreactivity than larger-diameter neurons. By in situ hybridization we detect RL-14.5 mRNA expression in all DRG neurons, whereas our previous immunocytochemical study detected significant immunoreactivity in only $63 \%$ of neuronal cell bodies. This discrepancy may be due to the differing sensitivity of the 2 techniques or to the selective degradation or transport of the lectin out of the cell bodies of some neurons. The present observations combined with previous immunocytochemical studies therefore suggest that in the PNS RL-14.5 is predominantly or selectively expressed in sensory neurons.
RL-14.5 mRNA also shows a highly restricted pattern of expression within the CNS. Specific hybridization was detected in motoneurons both in the spinal cord and brain stem. Hybridization to motoneurons in the spinal cord was first detectable by E13 and became more prominent by E18 (Fig. $5 b$ ). The intensity of hybridization in motoneurons increased during development with high levels of mRNA persisting in motoneurons in the adult spinal cord (Fig. 7). Within the brain stem, cranial nerve motoneurons, including the motor nucleus of the trigeminal nerve and the facial motor nucleus (Fig. 7), were intensely labeled. Labeled neurons were also observed in the trigeminal mesencephalic nucleus and the nucleus ambiguus. Brain-stem projection neurons in the cerebellar dentate nucleus and the vestibular nuclei exhibited low levels of hybridization. However, specific hybridization could not be detected in other regions of the brain, including areas such as the hypothalamus and cerebral cortex, where transcripts were detected by RNA blot analysis. Other neurons or non-neuronal cells within the central and peripheral nervous system may therefore express RL-14.5 mRNA, but at levels significantly lower than that de- 

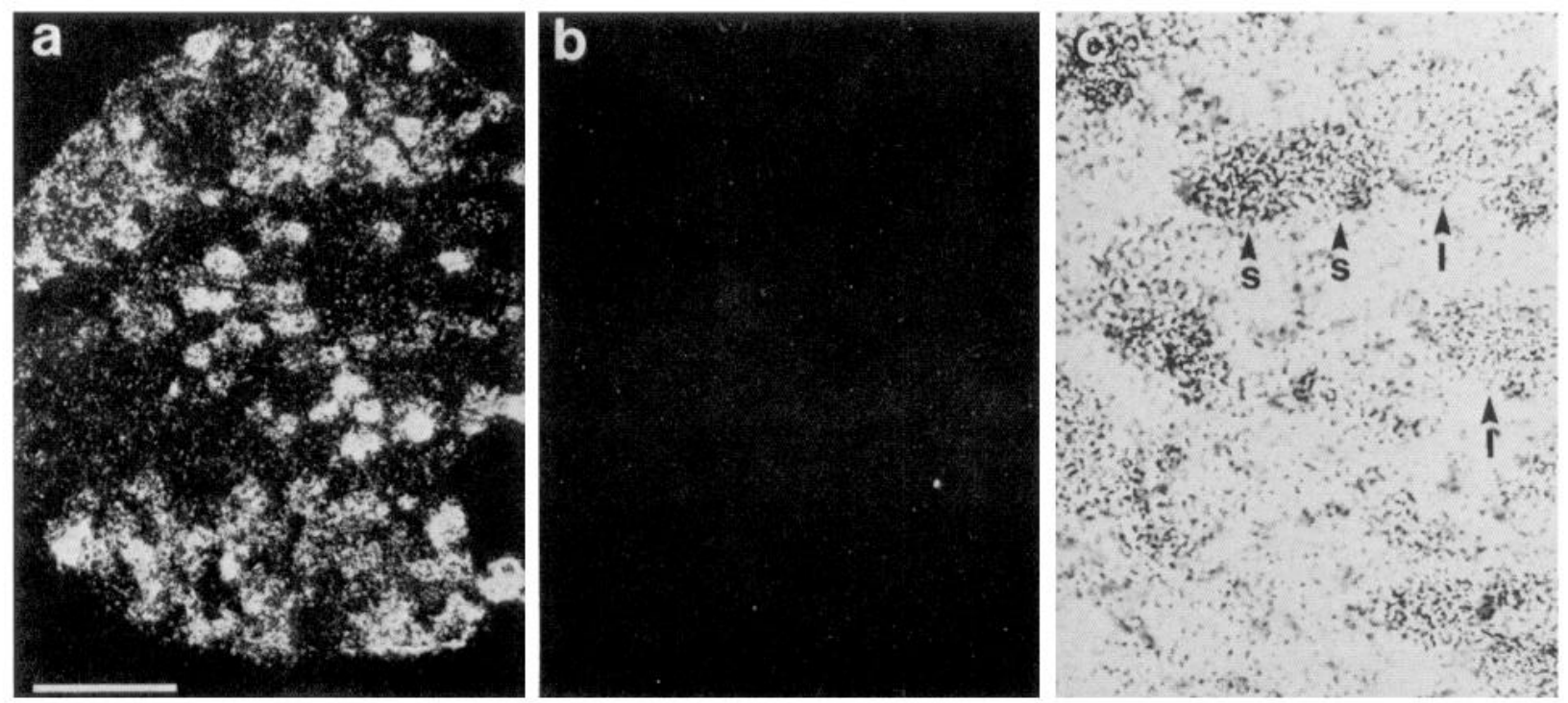

Figure 6. Localization of RL-14.5 mRNA in DRG neurons in the adult rat by in situ hybridization. $a$, Low-power, dark-field photomicrograph showing intense hybridization to sensory neurons of the adult rat DRG. Hybridization was detected in virtually all neurons in the adult rat DRG. Scale bar, $200 \mu \mathrm{m}$ in $A, 200 \mu \mathrm{m}$ in $B, 50 \mu \mathrm{m}$ in $C$. $b$. Hybridization to an adjacent section of adult rat DRG, using a ${ }^{35} S-l a b e l e d$ RNA probe transcribed from the sense strand of the RL-14.5 cDNA. No hybridization above background was detected. $c$, High-power, bright-field photomicrograph of adult DRG. Accumulation of silver grains in adult DRG consistently localized over DRG neuronal cell bodies and not over support cells within ganglion. The autoradiographic grain density was higher in small- and intermediate-diameter neurons $(S)$ than in large-diameter neurons $(I)$.

tected in sensory and motoneurons. Alternatively, these low levels of RL-14.5 mRNA may derive from other non-neural cells, for example, vascular smooth muscle cells or hematopoietic cells present in the CNS.

\section{Discussion}

Several lines of evidence suggest that cell surface carbohydrate structures may participate in cell-cell or cell-substrate interactions during nervous system development. Galactosyltransferases have been reported to bind to carbohydrates on extracellular matrix substrates and contribute to the migration of neural crest cells (Runyan et al., 1986). Ganglioside structures on developing neuroblasts have also been suggested to modify neural cell adhesion by regulating the interactions of these cells with extracellular matrix molecules such as fibronectin (Stallcup et al., 1989). Moreover, various complex oligosaccharide antigens and several carbohydrate binding proteins have been localized to specific subsets of developing neurons (Dodd et al., 1984; Levine et al., 1984; Dodd and Jessell, 1985; Yamamoto et al., 1985; Jessell and Dodd, 1986; Blum and Barnstable, 1987). In the present study, we provide further information on the structure and specificity of expression of one carbohydrate binding protein within the mammalian nervous system. The isolation of cDNA clones encoding the lactose-binding lectin RL-14.5 has established that this lectin is synthesized at high levels in a restricted subset of central and peripheral neurons. Within the nervous system, RL-14.5 mRNA is expressed at high levels in most or all motoneurons, and in primary sensory neurons of the trigeminal mesencephalic nucleus and at low levels in the cerebellar dentate and vestibular nuclei. Moreover, the expression of RL-14.5 mRNA occurs soon after neuronal differentiation, suggesting that this lectin, if secreted, could contribute to the interactions of developing sensory and motoneu- rons with other cells or extracellular matrix molecules in their environment.

\section{Structure of $R L-14.5$}

Two major classes of lectins have been identified in vertebrate tissues. The first comprises a large family of structurally related integral membrane and secreted proteins that require the presence of $\mathrm{Ca}^{2+}$ for their carbohydrate-binding function (Drickamer, 1988). This class includes the hepatic asialoglycoprotein receptor, macrophage mannose-binding proteins, a lymphocyte homing receptor, and several extracellular matrix proteoglycan core proteins (Drickamer, 1988). The second class, which includes RL-14.5, consists of smaller soluble lectins that do not require $\mathrm{Ca}^{2+}$ for carbohydrate binding and react predominately with lactosamine-based structures (Barondes, 1984, 1988). Members of this family of lectins lack signal sequences, although they appear to be secreted from at least some cells (Barondes, 1988). Although extensive sequence homology is apparent among members of each class, primary sequence homologies between the 2 classes are not seen even when the carbohydrate ligand seems to be the same. In addition, comparison of the sequence of RL-14.5 and related lectins with the sequence of galactosyltransferases (Narimatsu et al., 1986; Shaper et al., 1986) has not revealed any structural similarities.

The predicted amino acid sequence of the rat brain RL-14.5 lectin is identical to that of the rat lung lectin sequence reported by Clerch et al. (1988). This finding suggests that there is only one species of RL-14.5 which is common to neurons and nonneural cells (see also Abbott and Feizi, 1989). Isoforms of 14 $\mathrm{kDa}$ lactose-binding lectins detected by 2 -dimensional electrophoresis (Fitzgerald et al., 1984) may therefore reflect posttranslational modifications of the same core protein. However, several other lectins which are structurally related to RL-14.5 have 

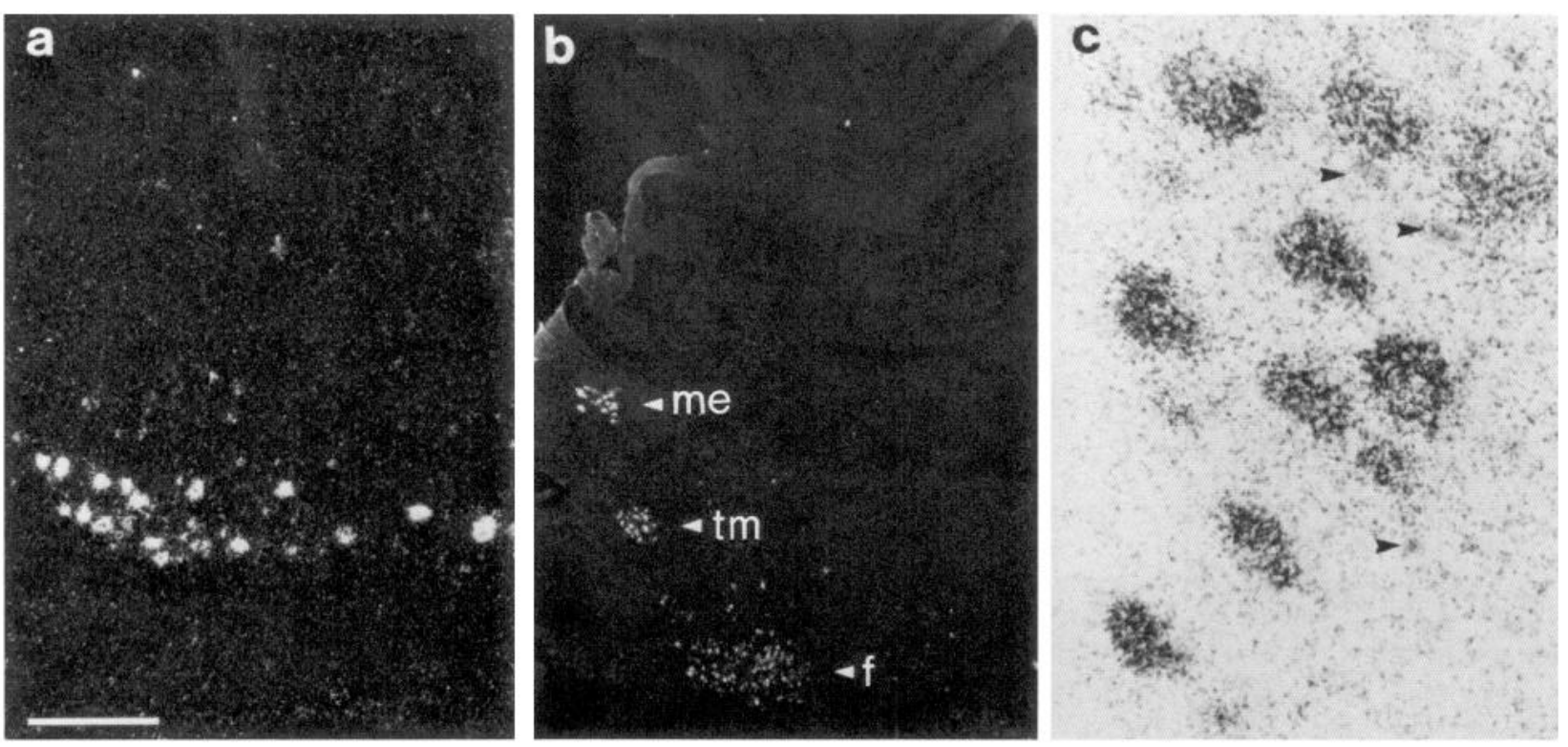

Figure 7. Localization of RL-14.5 mRNA within the central nervous system of the adult rat detected by in situ hybridization. $a$, Low-power, dark-field photomicrograph of a parasagittal section through adult rat spinal cord. Hybridization to RL-14.5 mRNA is detected over motoneurons in the ventral region of the spinal cord but not to any other cell type in the spinal cord. Scale bar, $200 \mu \mathrm{m}$ in $A, 500 \mu \mathrm{m}$ in $B, 50 \mu \mathrm{m}$ in $C$. $b$, Lowpower, dark-field photomicrograph showing hybridization neurons in the brain stem. The major nuclei illustrated in this photomicrograph are the facial nucleus $(f)$, the trigeminal motor nucleus $(\mathrm{tm})$, and the trigeminal mesencephalic nucleus (me). No labeling was detectable in the cerebellum. Faint labeling is detected over the neurons in the deep cerebellar nuclei. $c$, High-power, bright-field photomicrograph showing accumulation of silver grains over motoneurons in the brain stem. Counterstained non-neuronal cells show no labeling above background (arrowheads).

been identified within mammalian tissues. Lactose-binding lectins of 18 and $29 \mathrm{kDa}$ have been isolated from rat lung (Cerra et al., 1984). RL-29 appears to be identical to the IgE binding protein isolated from rat RBL cells (Albrandt et al., 1987) and the rat homolog of the CBP-35 lectin isolated from mouse 3T3 fibroblasts (Jia and Wang, 1988). Additional structurally related lactose binding lectins have also been identified in rat intestine (Leffler et al., 1989). The marked amino acid sequence homologies which exist among these distinct proteins (Fig. 2) clearly defines this group of lectins as a family of structurally and perhaps functionally related molecules.

\section{Selective expression of $R L-14.5$ within the nervous system}

The results of the present studies on the localization of RL-14.5 mRNA in the nervous system are consistent with immunocytochemical studies of the expression of RL-14.5 (Regan et al., 1986). The in situ hybridization studies presented have further demonstrated that the presence of the lectin in primary sensory neurons and in motoneurons reflects synthesis by the neurons themselves and not the accumulation of lectin synthesized by other central or peripheral cells. These studies also reveal that there is no detectable synthesis of the lectin by cells in the dorsal horn of the spinal cord at any stage of development. The high levels of RL-14.5 immunoreactivity detected in the dorsal horn of the embryonic and adult spinal cord therefore reflect the presence of the lectin in or around the central terminals of DRG axons. Although precise quantitation was difficult, it appears that the highest levels of RL-14.5 mRNA are present in DRG neurons with small- or intermediate-diameters, consistent with the protein expression pattern observed by immunocytochemistry (Regan et al., 1986). Within the spinal cord, RL-14.5 mRNA expression is restricted to motoneurons. RL-14.5 may therefore prove useful as an early marker of spinal motoneuron differentiation.

\section{Function of $R L-14.5$}

RL-14.5 and related lectins have been proposed to mediate interactions between non-neural cells expressing appropriate cell surface carbohydrate stuctures (Barondes, 1984).

The function of RL-14.5 in sensory and motoneurons is not clear. Previous studies have provided evidence that these lactose-binding lectins are released from non-neural cells (Beyer and Barondes, 1982; Cerra et al., 1984). Moreover, both RL14.5 and RL-29 appear to be released from rat DRG neurons maintained in dissociated cell culture (Hynes et al., unpublished observations). If RL-14.5 functions extracellularly, at least 3 modes of action can be considered. One function of RL-14.5 may be to cross-link lactosamine structures on the surface of DRG neurons. Under physiological conditions, RL-14.5 exists as a dimer and can agglutinate neuronal and non-neural cells (Barondes, 1984; Joubert et al., 1987). A variety of lactoseries structures are differentially expressed on functional subsets of DRG neurons (Jessell and Dodd, 1986; T. M. Jessell and J. Dodd, unpublished observations). Moreover, RL-14.5 has differential affinity for these structurally distinct lactoseries oligosaccharides (Leffler and Barondes, 1986). Thus, even though RL-14.5 is expressed by all DRG neurons, differences in the binding affinity of RL-14.5 to the distinct lactoseries structures expressed by subpopulations of DRG neurons (Dodd and Jessell, 1985) could result in the selective cross-linking of axonal subsets and in this way promote the fasciculation of functional subclasses of sensory afferents in the dorsal root. Alternatively, since both motoneurons and DRG neurons extend axons into the periphery, RL-14.5 may mediate interactions of sensory or 
motor axons with carbohydrate structures in the peripheral extracellular matrix. Lactoseries oligosaccharides have been detected on a variety of peripheral cells as well as on extracellular matrix proteins including laminin (Fujiwara et al., 1988). Finally, RL- 14.5 could exert a direct signaling action on sensory or motor neurons via its binding to cell surface lactoseries carbohydrates on growth cones.

It is also possible that RL-14.5 has an intracellular function in DRG and motoneurons. Immunocytochemical studies in both non-neuronal cells and in DRG neurons have indicated that RL-14.5 and RL-29 can be detected both in the cytoplasm and in the nucleus (Barondes, 1984; Regan et al., 1986). The recent observations that numerous nuclear proteins, including some transcription factors, are glycosylated (Holt and Hart, 1986; Jackson and Tjian, 1988), raises the possibility that one role of these lectins may be to regulate the function of nuclear proteins. Observations on the structure and location of CBP-35, the mouse homolog of RL-29, has provided some support for this idea. The amino acid sequence of CBP-35 deduced from cDNA cloning has revealed that the protein consists of 2 distinct domains. The carboxy-terminal domain exhibits homology to other soluble lactose-binding proteins; however, the amino-terminal region exhibits sequence similarity with proteins of heterogenous ribonucleoprotein complexes (Jia and Wang, 1988). Moreover, CBP-35 appears to be a component of ribonucleoprotein complexes in mouse 3 T3 cells (Laing and Wang, 1988).

The presence of RL-14.5 and RL-29 in both the nucleus and in the synaptic terminals of DRG neurons and the detection of the protein in secreted form suggest that these lectins may have multiple and diverse functions. The isolation of cDNA clones that encode RL-14.5 provides a basis for the design of cellular and molecular assays to assess the function of this protein in functionally distinct subsets of neurons.

\section{References}

Abhott, W. M., and T. Feizi (1989) Evidence that the $14 \mathrm{kDa}$ soluble $\beta$-galactoside-binding lectin in man is encoded by a single gene. Biochem. J. 259: 291-294.

Albrandt, K., N. K. Orida, and F.-T. Liu (1987) An IgE-binding protein with a distinctive repetitive sequence and homology with an IgG receptor. Proc. Natl. Acad. Sci. USA 84: 6859-6863.

Barondes, S. H. (1984) Soluble lectins: A new class of extracellular proteins. Science 223: 1259-1264.

Barondes, S. H. (1988) Bifunctional properties of lectins: Lectins redefined. Trends Biochem. 13: 480-482.

Beyer, E. C., and S. H. Barondes (1982) Secretion of endogenous lectin by chicken intestinal goblet cells. J. Cell Biol. 92: 28-33.

Bleil, J. D., and P. M. Wassarman (1988) Galactose at the nonreducing terminus of O-linked oligosaccharides of mouse egg ZP3 is essential for the glycoprotein's sperm receptor activity. Proc. Natl. Acad. Sci. USA 85: 6778-6782.

Blum, A. S., and C. J. Barnstable (1987) O-acetylation of a cell-surface carbohydrate creates discrete molecular patterns during neural development. Proc. Natl. Acad. Sci. USA 84: 8716-8720.

Brown, A. G. (1981) Organization in the Spinal Cord, p. 239, SpringerVerlag, New York.

Cerra, R. F., P. L. Haywood-Reid, and S. H. Barondes (1984) Endogenous mammalian lectin localized extracellularly in lung elastin fibers. J. Cell Biol. 98: 1580-1589.

Chirgwin, J. M., A. E. Przybyla, R. J. MacDonald, and W. J. Rutter (1977) Isolation of biologically active ribonucleic acid from sources enriched in ribonuclease. Biochemistry 18: 5294-5299.

Chou, D. K., J. Dodd, T. M. Jessell, C. E. Costell, and F. B. Jungalwala (1989) Identification of $\alpha$-galactose ( $\alpha$-fucose)-asialo GM 1 glycolipid expressed by subsets of rat dorsal root ganglion neurons. J. Biol. Chem. 264: 3409-3415.
Clerch, L. B., P. Whitney, M. Hass, K. Drew, T. Miller, R. Werner, and D. Massaro (1988) Sequence of a full-length cDNA for rat lung B-galactoside-binding protein: Primary and secondary structure of the lectin. Biochemistry 27: 692-699.

Couraud, P. O., D. Casentini-Borocz, T. A. Bringman, J. Griffith, M. McGrogon, and G. E. Hedwin (1989) Molecular cloning, characterization and expression of a human $14 \mathrm{kDa}$ lectin. J. Biol. Chem. 264: $1310-1317$

Dodd, J., and T. M. Jessell (1985) Lactoseries carbohydrates specify subsets of dorsal root ganglion neurons projecting to superficial dorsal horn of rat spinal cord. J. Neurosci. 5: 3278-3294.

Dodd, J., D. Solter, and T. M. Jessell (1984) Monoclonal antibodies against carbohydrate differentiation antigens identify subsets of primary sensory neurons. Nature 311: 469-472.

Drickamer, K. (1988) Two distinct classes of carbohydrate-recognition domains in animal lectins. J. Biol. Chem. 263: 9557-9560.

Eisenbarth, G. S., R. R. Ruffolo, Jr., F. S. Walsh, and M. Nirenberg (1978) Lactose sensitive lectin of chick retina and spinal cord. Biochem. Biophys. Res. Commun. 83: 1246-1252.

Fenderson, B. A., U. Zehavi, and S. I. Hakomori (1984) A multivalent lacto-N-fucopentose III-lysyllysine conjugate decompacts preimplantation mouse embryos, while the free oligo-saccharide is ineffective. J. Exp. Med. 160: 1591-1596.

Fitzgerald, J., J. W. Catt, and F. L. Harrison (1984) Isoforms of an endogenous lectin in rabbit bone marrow. Eur. J. Biochem. 140:137141.

Fujiwara, K., H. Shinkai, R. Deutzmann, M. Paulsson, and R. Timpl (1988) Structure and distribution of N-linked at oligosaccharide chains on various domains of mouse tumor laminin. Biochem. J. 252: 453461

Gitt, M. A., and S. H. Barondes (1986) Evidence that a human soluble B-galactoside-binding lectin is encoded by a family of genes. Proc. Natl. Acad. Sci. USA 83: 7603-7607.

Hirabayashi, J., and K. Kasai (1988) Complete amino acid sequence of a b-galactoside-binding lectin from human placenta. J. Biochem. 104: $1-4$.

Holt, G. D., and G. W. Hart (1986) The subcellular distribution of terminal $\mathrm{N}$-acetylglucosamine moieties. J. Biol. Chem. 261: 80498057.

Jackson, S. P., and R. Tijan (1988) O-Glycosylation of eukaryotic transcription factors: Implications for mechanisms of transcriptional regulation. Cell 55: 125-133.

Jessell, T. M., and J. Dodd (1986) Neurotransmitters and differentiation antigens in subsets of sensory neurons projecting to the spinal dorsal horn. In Neuropeptides in Neurologic and Psychiatric Disease, J. B. Martin and J. D. Barchas, eds., pp. 111-133, Raven, New York.

Jia, S., and J. L. Wang (1988) Carbohydrate binding protein-35, complementary DNA sequence reveals homology with proteins of the heterogeneous nuclear RNP. J. Biol. Chem. 263: 6009-6011.

Joubert, R., M. Caron, and D. Bladier (1987) Brain lectin-mediated agglutinability of dissociated cells from embryonic and post-natal mouse brain. Brain Res. 433: 146-150.

Kobiler, D., E. C. Beyer, and S. H. Barondes (1978) Developmentally regulated lectins from chick muscle, brain and liver have similar chemical and immunological properties. Dev. Biol. 64: 265-272.

Kuchler, S., C. Fressinaud, L. L. Sarlieve, G. Vincendon, and J.-P. Zanetta (1988) Cerebellar soluble lectin is responsible for cell adhesion and participates in myelin compaction in cultured rat oligodendrocytes. Dev. Neurosci. 10: 199-212.

Laing, J. G., and J. L. Wang (1988) Identification of carbohydrate binding protein 35 in heterogenous nuclear ribonucleoprotein complex. Biochemistry 27: 5329-5334.

Lasky, L. A., M. S. Singer, T. A. Yednock, D. Dowbenko, C. Fennie, T.-N. Rodriguez, S. Stachel, and S. D. Rosen (1989) Cloning of a lymphocyte homing receptor reveals a lectin domain. Cell 56: 10451055.

Leffler, H., and S. H. Barondes (1986) Specificity of binding of three soluble rat lung lectins to substituted and unsubstituted mammalian $\beta$-galactosides. J. Biol. Chem. 261: 10119-10126.

Leffler, H., F. R. Masiarz, and S. H. Barondes (1989) Soluble lactosebinding vertebrate lectins: A growing family. Biochemistry 28: 92229229.

Levi, G., and V. I. Teichberg (1981) Isolation and physiochemical characterization of electrolectin, a $\beta$-D-galactoside binding lectin from 
the electric organ of Electrophorus electricus. J. Biol. Chem. 261. 5735-5740.

Levine, J. M., L. Beasley, and W. B. Stallcup (1984) The D1.1 antigen: A cell surface marker for germinal cells of the central nervous system. J. Neurosci. 4: 820-831.

Lund, P. K., B. M. Moats-Staats, M. A. Hynes, J. G. Simmons, M. Jansen, A. J. D'Ercole, and J. J. Van Wyk (1986) Somatomedininsulin-like growth factor-I and insulin-like growth factor-II mRNAs in rat-fetal and adult tissues. J. Biol. Chem. 261: 4539-4544.

Maxam, A. M., and W. Gilbert (1977) A new method for sequencing DNA. Proc. Natl. Acad. Sci. USA 74: 560-564.

Maniatis, R., E. F. Fritsch, and J. Sambrook (1982) Molecular Cloning. A Lahoratory Manual, Cold Spring Harbor Laboratory, New York.

Narimatsu, H., S. Sinha, K. Brew, H. Okayama, and A. P. Qasba (1986) Cloning and sequencing of cDNA of bovine N-acetylglucosamine $(B, 1-4)$ galactosyltransferase. Proc. Natl. Acad. Sci. USA 83. $4720-4724$.

Ohyama, Y., J. Hirabayashi, Y. Oda, S. Ohno, H. Kawasaki, K. Suzuki, and K. Kasai (1986) Nucleotide sequence of chick 14K B-galactoside-binding lectin mRNA. Biochem. Biophys. Res. Commun. 134: 51-56.

Paroutaud, P., G. Levi, V. I. Teichberg, and A. D. Strosberg (1987) Extensive amino acid sequence homologies between animal lectins. Proc. Natl. Acad. Sci. USA 84: 6345-6348.

Perl, E. R. (1983) Characterization of nociceptors and their activation of neurons in the superficial dorsal horn: First steps for the sensation of pain. Adv. Pain. Res. Ther. 6: 23-51.

Rastan, S., S. J. Thorpe, D. P. Scudder, S. Brown, H. C. Gooi, and T. Feizi (1985) Cell interactions in preimplantation embryos: Evidence for involvement of saccharides of the poly- $\mathrm{N}$-acetyllactosamine series. J. Embryol. Exp. Morphol. 87: 115-128.

Regan, L., J. Dodd, S. H. Barondes, and T. M. Jessell (1986) Selective expression of endogenous lactose-binding lectins and lactoseries glycoconjugates in subsets of rat sensory neurons. Proc. Natl. Acad. Sci. USA 83: 2248-2252.

Rigby, P. W. J., M. Dieckmann, C. Rhodes, and P. Berg (1977) Labeling deoxyribonucleic acid to high specific activity in vitro by nick translation with DNA polymerase I. J. Mol. Biol. 113: 237-251.

Rosen, S. C., and T. A. Yednock (1986) Lymphocyte attachment to high endothelial venules during recirculation: A possible role for carbohydrates as recognition determinants. Mol. Cell Biochem. 72: 153164.
Runyan, R. B., G. D. Maxwell, and B. D. Shur (1986) Evidence for a novel enzymatic mechanism of neural crest cell migration on extracellular glycoconjugate matrices. J. Cell Biol. 102: 431-441.

Sanger, F., S. Nicklen, and A. R. Coulson (1977) DNA sequencing with chain-terminating inhibitors. Proc. Natl. Acad. Sci. USA 74. 5463-5467.

Shaper, N. L., G. F. Hollis, J. G. Douglas, I. R. Kirsch, and H. Shaper (1986) Characterization of the full length cDNA for murine B-1-4galactosyltransferase. J. Biol. Chem. 263: 10420-10428.

Siegelman, M. H., M. Van de Rijn, and I. L. Weissman (1989) Mouse lymph node homing receptor cDNA clone encodes a glycoprotein revealing tandem interaction domains. Science 243: 1165-1171.

Simpsom, D. L., D. R. Thorne, and H. H. Loh (1977) Developmentally regulated lectin in neonatal rat brain. Nature 266: 367-369.

Snyder, M., and R. W. Davis (1985) Screening $\lambda g t 11$ expression libraries with antibody probes. In Hybridoma Technology with Biosciences and Medicine, T. A. Springer, ed., pp. 397-406, Plenum, New York.

Stallcup, W. B., R. Pytela, and E. Ruoslahti (1989) Neuroectodermassociated ganglioside participates in fibronectin receptor-mediated adhesion of germinal cells to fibronectin. Dev. Biol. 132: 212-229.

Vierira, J., and J. Messing (1982) The pUC plasmids, an M13mp7derived system for insertion mutagenesis and sequencing with synthetic universal primers. Gene 19:259-268.

Wassarman, P. M. (1987) Early events in mammalian fertilization. Annu. Rev. Cell Biol. 3: 109-142.

Weinstock, R., T. Sweet, M. Weiss, H. Cedar, and R. Axel (1978) Intragenic DNA spacers interrupt the ovalbumin gene. Proc. Natl. Acad. Sci. USA 75: 1299-1303.

Wilson, T. J. G., M. N. Firth, F. L. Harrison, and J. T. Powell (1989) Studies on the cDNA of the mouse $14 \mathrm{~K} \beta$-galactoside lectin. Biochem. Soc. Trans. (in press).

Yamamoto, M., A. M. Boyer, and G. A. Schwarting (1985) Fucosecontaining glycolipids are stage and region-specific antigens in developing embryonic brain of rodents. Proc. Natl. Acad. Sci. USA 82 . 3045-3049.

Young, R. A., and R. W. Davis (1983) Efficient isolation of genes by using antibody probes. Proc. Natl. Acad. Sci. USA 80: 1194-1198.

Zanetta, J. P., A. Meyer, S. Kuchler, and G. Vincendon (1987) Isolation and immunochemical study of a soluble cerebellar lectin delineating its structure and function. J. Neurochem. 49: 1250-1257. 